\title{
Innovative Opportunities and Reserves of Contemporary Marketing Communication
}

\begin{abstract}
Submitted 21/01/19, $1^{\text {st }}$ revision 24/02/19, $2^{\text {nd }}$ revision 04/04/19, accepted 25/05/19
Prikhodko K.S. ${ }^{1}$, Danilevskaya E.N. ${ }^{2}$, Savina K.S. ${ }^{3}$, Shupenko R.E. ${ }^{4}$ Abstract:

Purpose: The article aims to present characteristics and research of peculiarities, forms and categories of innovative communication, as well as to evaluate the reasons for the decline in the effectiveness of traditional marketing communication.

Design/Methodology/Approach: The article considers the existing practice of creative implementation of theoretical and applied marketing knowledge in the activities of organizations. The paper substantiates contemporary and perspective innovative concepts and tendencies of marketing communication.

Findings: The manuscript highlights the reasons for changing the classical marketing paradigm and the direction of innovative development of communication interaction concepts. In the course of enterprise's innovative development management marketing assumes a new dimension and plays a special role in the management process. The role of traditional means of communication has declined with the development of Internet technologies, the use of interactive personalized marketing communication with consumers and the personalization of communication influences has become increasingly popular.

Practical implications: Current trends in the development of relationship marketing are characterized by a significant increase in the role of such an important component of its complex as "promotion", as well as the intensification of the development and implementation of innovative technologies and tools.

Originality/Value: The originality of this approach consists in the analysis of the features and prospects of the innovative development of the marketing and communication sphere.
\end{abstract}

Keywords: Relationship marketing, marketing communication, innovative marketing tools.

JEL Codes: D10, D11, D12, D30, D39.

Paper Type: Research article in a Special Issue dedicated to Russian Economy.

Section 8: Business and Economic Issues.

${ }^{1}$ PhD, Associate Professor of the Department of Economics and Management, Krasnodar Affiliate of the SBFEI HE "Plekhanov Russian University of Economics",

Sergiyanks@mail.ru

${ }^{2}$ Senior Professor of the Department of Trade and Catering, Krasnodar Affiliate of the

SBFEI HE "Plekhanov Russian University of Economics”, danilevskaja@ mail.ru

${ }^{3}$ Senior Professor of the Department of Economics and Management, Krasnodar Affiliate of the SBFEI HE "Plekhanov Russian University of Economics”, savina@mail.ru

${ }^{4}$ External PhD student of the Department of Marketing and Commerce of the FSBFEI HE

“Kuban State University”, shupenko@mail.ru 


\section{Introduction}

Marketing communication is considered to be the process of transmitting target information to a product or service. Effective communication has become a key factor for the success of any organization, since it is marketing communication that inform potential customers about the product or service, convince the buyer to give preference to these products or services, act in the interests of the company. New conditions and factors of the effectiveness of marketing activities are constantly emerging in the modern marketing environment, which leads to the emergence of innovative tools used to promote products.

\section{The Role of Integrated Marketing Communications}

Marketing communication can now be called the most effective marketing tool, including the practice of communicating information necessary for an enterprise to create a positive market image to actively generate demand for the products offered. There is a wide range of alternative tools for marketing communication, such as advertising, personal selling, direct marketing, loyalty programs, exhibitions, sponsorship, communication, public relations and other activities. Their modern development and adaptation to a dynamic market in the new economic conditions is of high importance.

Integrated marketing communication (IMC) is the most relevant concept of comprehensive brand promotion (product, company), which involves the combined use of all available types of communications in marketing. They help human needs to be formed and actualized, its values to be formulated. Individual firms, organizations, institutions, suppliers, possible intermediaries, existing or potential competitors, as well as the recipient to whom information transmitted through marketing communication is addressed, are considered to be the subjects of marketing communication. These links form the so-called communicative network (Gugnina et al., 2016).

The place and role of marketing communication are determined by their main subject - information transmitted in the process of marketing activities. The exchange of information does not always lead to the mutual agreement of market counterparties. The main reason for the low effectiveness of traditional marketing communication lies in the underestimation of its role in the exchange of information, which occurs only when one side offers information and the other perceives it.

This circumstance leads to a kind of integrative role of marketing communication performed in relationship marketing, which can be justified by the following major points: 
- the development of marketing theory, the emergence of the concept of integrated marketing communication in it as an independent field of scientific knowledge;

- the development of marketing technologies, combining all forms, methods and tools to promote information, product, work, services into a single system;

- the evolutionary development of marketing communication, the enrichment of their content and the variety of ways to transmit information with the increasing importance of contacts implemented in the virtual environment;

- manifestation of synergy of the integrated use of marketing communication channels by all subjects of marketing activities provided by modern technologies for the transmission, processing and analysis of information for making management decisions;

- creation of a favorable environment for the exchange of marketing information between the subjects of the consumer market, created with the active support of the media, individualizing advertising messages to target audiences of consumers in various media.

The cumulative expression of these reasons is accompanied by the formation of a holistic communication mechanism creating an integrative framework for the development of relationship marketing.

It is necessary to consider the full significance of the development of marketing communication. It is directly related to the development of science and technology, new inventions, the socio-economic situation in the world and in a separate state, as well as to the general political state in society. Of course, marketing innovations are becoming very important (Korolyova, 2007). It is feasible to highlight the basic "rules" of integrated marketing communication in business organization:

- first of all, it is needed to think about customers, surround the entire process of purchasing goods by the consumer with means of communication, determine the stages that it takes before, during the acquisition process and after its completion, choose communication tools suitable for each stage;

- all means of marketing communication should help to establish stronger ties with consumers, because retaining an existing consumer is just as important as gaining a new one;

- there is a need to create a reliable marketing information system that will allow determining who, when and what information is needed;

- it is important to be ready to change everything, learn from personal experience, constantly look for the optimal program of marketing activities.

Thus, it is possible to make a conclusion that integrated marketing communication is an integrated approach to running a business, allowing maximizing the use of all the tools available today. 


\section{Foundations of the Transformation of the Traditional Marketing Paradigm}

Many researchers of communication processes in modern society argue about the "extinction" of traditional means of marketing communication, mainly due to the loss of effectiveness of such major channel of marketing communication as advertising. Innovative marketing communication are becoming a new productive, driving force in modern society (Stepchenko, 2015). Some negative features of the classic means of marketing communication having led them to their logical transformation can be identified:

- lack of specifics and knowledge of the target audience;

- obsession with traditional means of marketing impact on consumers;

- fragmentation of the legal and managerial base;

- low-quality advertising material;

- irritation due to the frequency and uniformity of advertising messages;

- disagreement with other means of marketing communication;

- the use of untargeted marketing in the course of marketing communication;

- changes in consumer attitudes and consumer climate and, as a result, a decrease in the effectiveness of classic marketing tools to promote products;

- irresponsibility of the advertiser: lack of ethics and morality;

- the increased role of "word-of-mouth": the growth of confidence in the feedback from friends and acquaintances, and not in advertising;

- short-term and inadequate impact of one channel of marketing communications;

- a constantly changing market and a huge number of homegenous goods.

There is no convincing retraction of the loss of traditional marketing, although the alternative is new marketing - unconventional, based on innovative principles and approaches, i.e. innovative. The evolution of the innovative theory of marketing is associated primarily with the emergence of new types of marketing that form nonstandard (non-traditional) approaches to the activities of companies in the market.

The IMC complex provides a number of advantages over single means of promotion:

- the systemic approach to promotion (synergy) - the impact of the communication components as a whole is greater than the sum of these communications separately, due to the fact that each link of this system has mutual influence on each other;

- leveling the deficiencies of some of facilities being a part of the complex due to the positive qualities of others;

- consolidation, focusing and optimization of the company's efforts in advancing and exiting crisis situations;

- saving budget funds with a more efficient supply of the brand / product / service;

- promotion control carried out at different stages from one centre (department or division of the company's marketing); 
- high-quality contact with the audience;

- effective time of impact on the audience;

- development of a common tactics and promotion strategy for all channels;

- accounting for all marketing communications of unified promotion standards;

- informing target audiences, whose search is facilitated by compiling data from all marketing communications;

- stronger and weighted positions in a competitive market;

- study of all aspects of brand promotion, etc.

The above arguments in favor of the view that traditional marketing tools have become obsolete have shown that modern communications have a lot of work to do in the field of a buzzword "collaboration" of various means of promotion with each other. The changed type of consumer and the ever-changing market conditions have led to the need of two-way communication, establishing constant communication in the "producer-buyer" system, in conditions of complete awareness, and through the clear and consistent integration of all channels of circulation. All this leads to the idea that the IMC complex is the path which the marketing communication tools should follow.

\section{Fundamentals of Organization and Implementing Innovative Marketing Communication}

Innovations imply all novelties and changes in any activity, their application and benefit from their use. Innovations include additional, radical and revolutionary changes in mental processes, in the production of new products and the provision of services. Innovations can be carried out not only in economic processes, but also manifest themselves in design, technological, social and technical activities. Innovations in the organizational sphere are associated with an increase in productivity, product quality, high efficiency, with greater competitive opportunities and a larger market share.

Innovative marketing today is the most important activity in the life of any company. By improving the product and making a search for new marketing moves, the company can significantly increase its market share and, accordingly, increase its revenue. In the current context, companies perceive marketing not as a separate function of corporate governance, but as a concept for managing innovative development and emphasize the use of innovative marketing in management activities.

Marketing, as one of the most important activities of the company, requires the intensive use of innovative tools. Development and implementation of marketing innovations in the current context is the most effective, if not the only, way to increase competitiveness and maintain high rates of company development. Marketing innovations are aimed at better satisfying the needs of the company's customers, expanding its customer base, and stimulating the marketing of products and services, 
which as a result leads to an increase in their sales and gaining a larger market share by the company (Shpakova, 2011).

The advantages of using innovative marketing communication tools are the following:

- attracting attention by its extraordinariness;

- innovation distinguishes the leader from the following businesses;

- an individual approach to solving the problem of the buyer;

- the ability to conquer the market in a short time;

- inconspicuous impact on the consumer;

- formation of a client database;

- increasing consumer loyalty;

- in some cases - saving the budget of marketing communications (Shpakova, 2011).

The most common methods and techniques of innovative marketing are guerrilla, viral, connected, buzz, word-of-mouth, social networks, blogs, sponsored marketing, provocative marketing, product placement and its subcategory - life placement, ambient marketing and many others. The current trend is also the integration of marketing communication into social networks (SMM). Of course, the effectiveness of many tools indicated above is extremely difficult to measure, it also requires audience surveys, counting clicks (but they do not always mean interest), some quantitative and qualitative research (Shpakova, 2011).

In the course of managing the innovative development of an enterprise, marketing assumes new dimension and plays a special role in the management process. For the most part, this is related to the peculiarities of the most innovative activity, which is a venture in its essence and does not guarantee a positive result. With the development of Internet technologies, the role of traditional means of communication has declined. The use of interactive personalized marketing communications with consumers has become increasingly popular. In turn, the development of interactive information technologies subjects to the personalization of marketing communications.

Innovations in marketing communication do not have to be a radically new way of marketing; they can also be minor changes in current tools. Marketing innovation is to update, change, or introduce completely new methods. New ideas, concepts, tools, methods, and strategies are not required every time, and the marketing strategies already used can still be considered innovative if they are successful again. If new communication strategies have been implemented or the existing ones have been updated or changed, and the set goals of enterprises have been achieved, then an assumption that innovations have been applied can be made.

It is customary to talk about alternative marketing (AM) in the international marketing environment. AM is the promotion of a company, a brand, a product or a service in the market using non-standard (otherwise called creative) methods and tools. Modern 
marketing can be differentiated based on using digital marketing techniques: using BigData; conversion increase; ad impressions (social media retargeting); contextual advertising; PR on the Internet; CRM marketing; SEO.

Domestic innovative marketing is facing some problems, the main problem called the lack of government support for innovative marketing organizations. According to experts, it is the support from the state that will help businessmen to pay attention to the field of innovative marketing. As a result, there will be healthy competition; large enterprises will have to set up innovative communication channels for sales to take a leading position.

The current stage of domestic marketing development is already marked by the emergence of marketing innovations, which include, for example:

- using artificial intelligence - the usual messages on the website are replaced by chat bots characterized by their personalization. Marketers are starting to introduce online consultants such as Intercom and Drift to better work with customers;

- personalization of messages - thanks to Account-Based Marketing (ABM) it is possible to create messages for each person, taking into account individual interests. Using platforms such as Adobe and Optimizely, marketers customize advertising in social networks for the client in the form of a specific piece of content;

- quantum marketing is becoming the mainstream. It does not offer a certain fashionable way of promotion, which has worked for two or three companies. This is the first attempt to comprehend all the ways to promote and understand when they work and when they do not work.

The basic assumption of quantum marketing is that there are patterns that are in no way connected with such a concept as creativity or even positioning that determine success in marketing;

- using blockchain - thanks to the use of the adChain platform, it will be possible to place advertisements on websites that do not use fraudulent schemes;

- integrating marketing activities into the human life cycle - its goal is to create a manageable strategy of contacts or communications with the help of persistently analyzed appeals and retargeting to support future and current customers on their way to making a purchase;

- brands are starting to develop content for voice search.

According to Google data, last year $20 \%$ of online queries were made via voice search. It is expected that by 2020 this number will increase to $50 \%$. At one time, marketers optimized content for Web 2.0 and mobile devices. Now they will have to do the same for voice search. Forecasting analytics makes marketers rethink plans. Thanks to analytics, marketers can identify potential customers to understand how to turn them 
into buyers. It is only an e-mail address that is needed, and tools like Infer will "scan" the web pages and find signs of readiness to make a purchase.

It is possible that there will be other unexpected marketing discoveries soon, and some of the forecasts will probably not bring results, as technology and consumer expectations are constantly changing. Marketing will rely more on analytics and continue to use organic search, voice search and various social networks. In addition, new content formats, such as augmented reality and in-car advertising will evolve and spread.

\section{Conclusion}

Current trends in the development of relationship marketing are characterized by a significant increase in the role of such an important component of its complex as "promotion", as well as the intensification of the development and implementation of innovative technologies and tools in the company's marketing communications system.

The description of innovations in marketing communications as a type of innovation activity creates a methodological basis that makes it possible to use the developments of innovation management in the field of marketing and communication management. All means of mass marketing communications should become more individual (personalized), that is, to act with their appeals only to target consumers.

\section{References:}

Gugnina, E.V., Sidunova, G.I., Samsonova, E.V., Samsonova, M.V. 2016. Innovative marketing technologies as a tool to improve the competitiveness of the organization. Fundamental Research. 10-1, 124-128.

Korolyova, I.V. 2007. Integrated marketing communications. Service in Russia and overseas, $3,141-146$.

Shpakova, A.V. 2011. Innovation factor of sustainable development of commercial enterprises. Abstract of $\mathrm{PhD}$ (Econ.) thesis, Bryansk.

Stepchenko, T.S. 2015. "Embedding into the body" as one of the tools of non-traditional marketing communications. Practical Marketing, 1, 47-52. 